\title{
Determination and mapping of cadmium accumulation in plant leaves on the highway roadside, Turkey
}

\author{
Merve Çolak ${ }^{1}$, Mahnaz Gümrükçüoğlu ${ }^{1 *}$, Füsun Boysan ${ }^{1}$, Erkan Baysal ${ }^{2}$ \\ ${ }^{1}$ Sakarya University, Turkey \\ Environmental Engineering Department \\ ${ }^{2}$ IZAYDAŞ, Solaklar Köyü Mevkii, Kocaeli, Turkey
}

*Corresponding author's e-mail: mahnaz@sakarya.edu.tr

\begin{abstract}
Keywords: accumulation, cadmium, emission inventory, GIS, plant leaves.
Abstract: This study investigates cadmium (Cd) accumulation in the plant leaves of juglans regia (walnut) and cydonia oblanga (quince) trees related to traffic emissions on the highway roadside. The plant leaf samples were collected from 20 sites on the D-100 Highway roadside and washed with deionized water before analyzed. Determination of $\mathrm{Cd}$ was carried out using an inductively-coupled plasma-mass spectrometer after microwave digestion of the samples. Cd concentration on the plant leaves was found to be between $0.04-0.11 \mathrm{mg} / \mathrm{kg}$. In order to determine the traffic-based emissions, vehicles were counted and an emission inventory was prepared. 0.18 tons of $\mathrm{Cd}$ was found to be delivered into the atmosphere every day. $\mathrm{Cd}$ accumulation depends on traffic density because there were no residential area and industrial plants. The distribution of $\mathrm{Cd}$ accumulation caused by traffic emissions was mapped by using a geographic information system (GIS). The maps showed that the $\mathrm{Cd}$ accumulation was high in the areas near the highway and then gradually decreased by moving away from the highway.
\end{abstract}

\section{Introduction}

It is well known that the concentration of trace elements in soil, water and air continues to increase due to numerous variable factors, such as industrial activities, traffic emissions and domestic waste. Many trace elements are present in petrol, deisel oil and are emitted by vehicle exhaust. It is known that these trace elements have the potential to accumulate in plants, animals, other living organisms and soil. Even a minimal concentration of some trace element ions like cadmium $(\mathrm{Cd})$, lead $(\mathrm{Pb})$ and arsenic (As) is toxic to living organisms (Mendil and Tuzen 2011).

Trace elements accumulation in plants growing on roadsides is mainly due to heavy traffic on roads. The amount of accumulated metals depends on the density of the traffic, terrain structure (steep/gradient, flat), terrain area (junction, main road side, etc.), part of the plant (leaf, stem, fruit) and the direction of the wind. Sisman et al. (2002) found that the accumulation of metals is higher in steep areas than in flat areas.

A great proportion of $\mathrm{Cd}$ that reaches the plants and soil is due to the precipitation of $\mathrm{Cd}$ that is in the air in the form of little dust particles. More than $40 \%$ of the accumulated $\mathrm{Cd}$ in plants near industrial and heavy traffic areas comes from the air (EPA 1987, Sharma and Dubey 2005). It has been calculated that the annual amount of $\mathrm{Cd}$ particles precipitated in roadside soil in heavy traffic areas is $0.2-1 \mathrm{mg}$ per $\mathrm{m}^{2}$ (EPA 1987).
The effects of $\mathrm{Cd}$ on the environment and human health are well-known. $\mathrm{Cd}$ is nonessential trace element for plants when compared to other trace elements and it is 2-20 times more toxic than the others. More than $3 \mathrm{mg} / \mathrm{kg}$ of $\mathrm{Cd}$ has a toxic effect in soil, while more than $1 \mathrm{mg} / \mathrm{kg}$ is toxic to plants on a dry matter basis (Benavides et al. 2005). Cd mostly accumulates in the leaves of plants. Plants can take up Cd ions both metabolically as well as passively, and $\mathrm{Cd}$ ions can easily be transported within the plant. Especially organic substances can easily absorb $\mathrm{Cd}$ ions and so $\mathrm{Cd}$ can be found at high concentrations in the leaves and roots. In unpolluted areas, $\mathrm{Cd}$ levels in plants are in the range of 0.01 and $0.03 \mathrm{mg} / \mathrm{kg}$.

There have been numerous studies investigating trace element accumulation in roadside plants that have generally focused on lead accumulation. Some of these woody and herbaceous plants include pine, oleaster, acacia, cypress, cedar, corn, oleander, grass and lettuce. As a result, the amount of lead accumulated is greater in dense traffic areas. Hence, there is a direct correlation between the lead accumulation, the density of the traffic and air circulation; as the distance from the highway increases, the amount of accumulated lead decreases (Yassoglou et al. 1987, Onasanya et al. 1993, Xiong 1997, Onianwa et al. 2002). In other studies, the accumulation of $\mathrm{Cd}, \mathrm{Cr}, \mathrm{Fe}, \mathrm{Mn}, \mathrm{Cu}, \mathrm{Ni}, \mathrm{As}, \mathrm{Sn}$, Ti and $\mathrm{Zn}$ elements in roadside woody and herbaceous plants was investigated and their concentrations were found to be higher than the normal level on the roadside and accumulation decreased away from 
the highway (Haktanır et al. 1995, Sawidis et al. 1995, Aksoy et al. 1997, Chronopoulos et al. 1997, Luilo et al. 2003, Staszewski et al. 2015). However, in these studies, emission inventories were not prepared for the explanation of trace element accumulation due to transportation vehicles. Also, the emission correlation analysis results were not mapped using GIS software.

The aim of this study was to investigate Cd accumulation in tree leaves in a dense traffic area on the D-100 main highway between Kocaeli and Sakarya in the northeast of Turkey. The leaves were collected and analyzed in the laboratory. The vehicle inventory was created and the distribution of $\mathrm{Cd}$ accumulation was mapped by using GIS software. Cd accumulation in plants as a result of exposure to vehicle emissions should be monitored due to the negative effects on human and environmental health.

\section{Material and Method}

\section{Study field}

The study field is located $29^{\circ} 57^{\prime}-30^{\circ} 53^{\prime} \mathrm{E}$ longitude, $40^{\circ} 17^{\prime}-41^{\circ} 13^{\prime} \mathrm{N}$ latitude, of the sea level. Throughout the study field the climatic characteristics of the Marmara and Black sea regions are apparent. The winter involves heavy rainfall and warm temperatures, while the summer is generally hot. The dominant are northeastern and northwestern winds. The study area is the roadside of the D-100 highway between the cities of Sakarya and Kocaeli where there is heavy traffic. This highway is generally used by intercity transport vehicles and TIR trucks. There are no residential areas, industrial plants or traffic lights close to the study area (Figure 1). There is considerable pollution from road traffic. Air pollution related to traffic is important in this study because the study area is located on the roadside covered by quince and walnut trees.

\section{Sample selection and analysis}

Quince and walnut trees have been cultivated as commercial agricultural activities in the study area. Quince and walnut trees were selected as samples because they are perennial plants and cover large area, being used in commercial areas (Wittig 1993).

The plant leaves were collected from D-100 highway, transferred to the laboratory and washed with deionized water. The leaf samples were collected randomly from 20 trees (10 walnut and 10 quince trees) as shown in Figure 1 and the sample point coordinates were identified with a Global Positioning System (GPS). The sampling was started at the edge of the highway and moved away step by step. 20 samples at least were taken from the sides of branches of each tree overlooking the road. The samples were collected from points between $50-500 \mathrm{~m}$ away from the highway.

As in many previous studies, the leaf samples were transferred to the laboratory and washed briefly and rinsed two times with deionized water in order to remove any dust and particles from the leaf surface (Onder et al. 2006, Karademir 1992, Kinalıglu et al. 2009). All samples were dried at $80^{\circ} \mathrm{C}$ in oven (Nüve, model, Ankara, Turkey) for 24 hours, then ground using a porcelain mortar and stored in plastic bags.

In order to validate the determination method for Cd levels used in this study, a standard reference material tobacco leaf was utilized and certified and the obtained values were 1.52 and $1.46 \mathrm{mg} / \mathrm{g}$, respectively. The recovery was calculated to be $96 \%$. The found value corresponds well with the certified value and hence, the method could be used reliably for the determination of $\mathrm{Cd}$ levels in the leaf samples.

The $\mathrm{Cd}$ concentrations were determined using ICP-MS after digestion of the samples in a microwave digestion system. For this purpose, leaf samples $(0.2 \mathrm{~g})$ were weighed with a sensitivity of $0.1 \mathrm{mg}$ and then dissolved in a microwave digestion system (Topwave, Analytik Jena AG, Jena, Germany) by adding $7 \mathrm{~mL}$ of $\mathrm{HNO}_{3}(65 \%), 1 \mathrm{~mL}$ of $\mathrm{H}_{2} \mathrm{O}_{2}(30 \%)$ and $0.5 \mathrm{~mL}$ of $\mathrm{HF}(40 \%)$. The final volume was completed with $50 \mathrm{~mL}$ of the obtained solution. In order to check the accuracy of the method, a certified reference material tobacco leaf

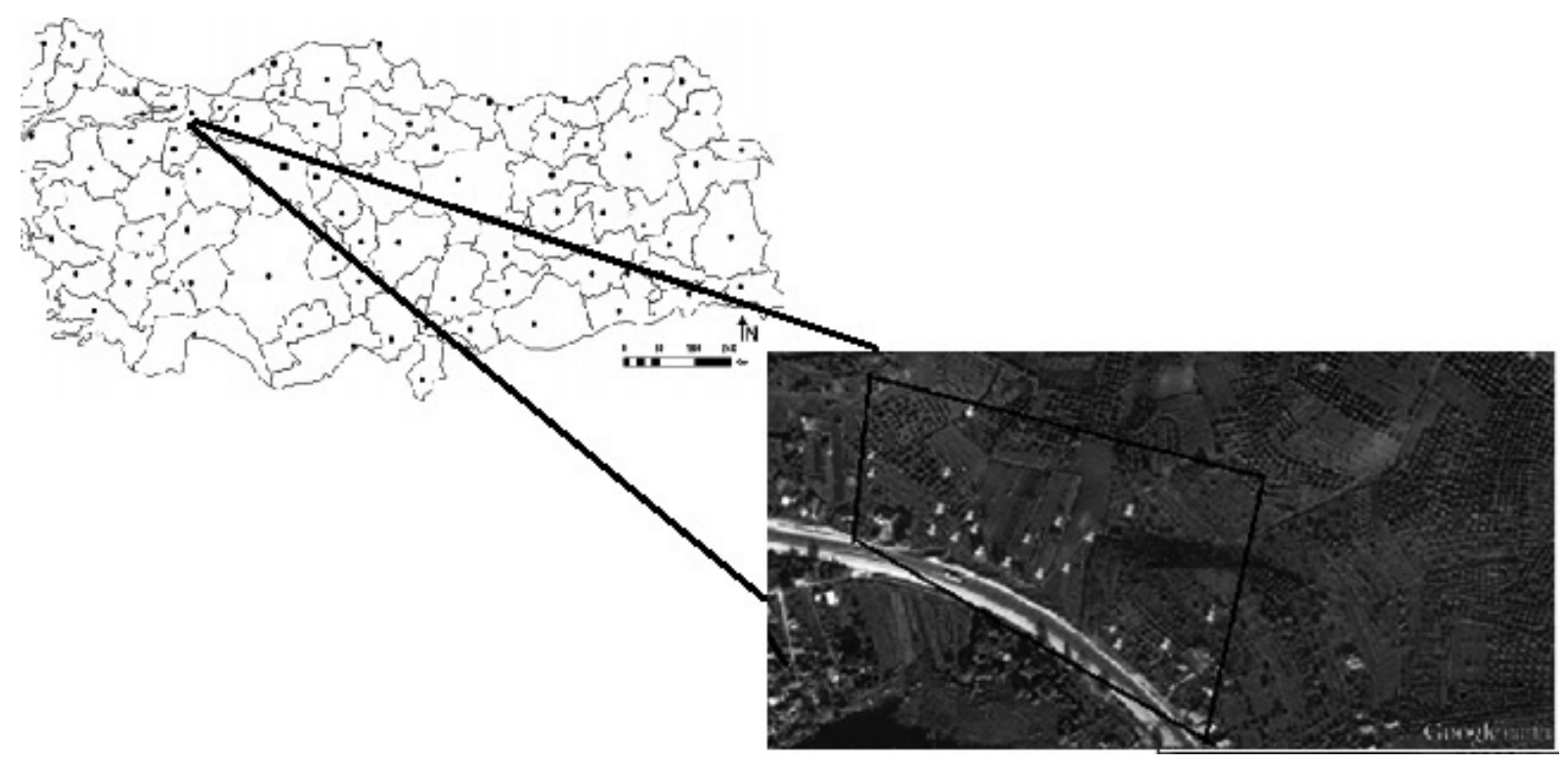

Fig. 1. Study area and points of sample collected 
(Virginia Tobacco Leaves, CTA-VTL-2) was dissolved under the same conditions.

$\mathrm{Cd}$ concentration in the obtained solution was measured using an inductively-coupled plasma-mass spectrometer (ICP-MS, Agilent 7500cx; Agilent Technologies, CA, USA). The $\mathrm{Cd}$ concentration of the leaf samples and certified reference material tobacco leaf were calculated in $\mathrm{mg} / \mathrm{kg}$.

\section{Preparation of the emissions inventory related to traffic}

The vehicle emissions inventory was calculated and prepared for the observation of the contribution of traffic on the $\mathrm{Cd}$ accumulation in the studied area. The purpose of the emission inventories was to identify air pollutant sources and the amount of pollutants released into the atmosphere from these sources. In this way, more effective results and recommendations could be produced for air pollution control and air quality (Elbir et al. 2001).

In this study, only heavy vehicles were included in the assessment for the calculation of emission inventory. The engine of commercial vehicles takes more fuel and gives off more emissions with increased load amount. Moreover, in order to recognize vehicles using diesel oil more easily in vehicle counting, heavy vehicles using this kind of fuel were taken into account. Diesel oil is one of the important sources of Cd (Sanda 1993).

In the first part of the inventory study, vehicle counts were conducted in order to determine the intensity of the highway traffic. Vehicle counting was carried out over four different high traffic density hours during the day and vehicles were counted by two persons. The emission factor for $\mathrm{Cd}$ was taken from the 2009 EMEP/EEA mission inventory guidebook (Table 1).

Table 1. Emission factor for cadmium (EMEP/EEA 2010)

\begin{tabular}{|c|c|}
\hline Category & Cadmium \\
\hline Passenger cars, gasoline & 0.01 \\
\hline Passenger cars, gasoline catalyst & 0.01 \\
\hline Passenger cars, diesel & 0.01 \\
\hline Passenger cars, LPG & 0.0 \\
\hline LDVs, gasoline & 0.01 \\
\hline LDVs, gasoline catalyst & 0.01 \\
\hline LDVs, diesel & 0.01 \\
\hline HDVs, gasoline & $\mathbf{0 . 0 1}$ \\
\hline HDVs, diesel & $\mathbf{0 . 0 1}$ \\
\hline Motorcycles $<50 \mathrm{~cm}^{3}$ & 0.01 \\
\hline Motorcycles $>50 \mathrm{~cm}^{3}$ & 0.01 \\
\hline
\end{tabular}

In order to move a vehicle, it has to have mechanical pulling power to support acceleration, uphill climbing, rolling resistance and wind resistance. The necessary power for acceleration and hill climbing is quite high compared to the others. Therefore, the region's elevation change and acceleration are important for fuel consumption and emissions. Vehicle emissions were calculated using Formulas 1 and 2.

$$
\dot{\mathrm{W}}_{\text {Total power of vehicle }}=\dot{\mathrm{W}}_{\text {slope }}+\dot{\mathrm{W}}_{\text {acc. }}+\dot{\mathrm{W}}_{\text {roll. }}+\dot{\mathrm{W}}_{\text {wind }}
$$

$\dot{\mathrm{W}}_{\text {slope. }}\left(\dot{\mathrm{W}}_{\text {uphill }}\right)=m \cdot g \cdot V \cdot \sin \Theta$

$\dot{\mathrm{W}}_{\text {acc. }}^{\text {slope. }}\left(\dot{\mathrm{W}}_{\text {accelaration }}\right)=m \cdot a \cdot V$

$\dot{\mathrm{W}}_{\text {res. }}^{\text {acc. }}\left(\dot{\mathrm{W}}_{\text {rolling resistance }}\right)=m \cdot g \cdot C_{\text {roll. }} V$

$\dot{\mathrm{W}}_{\text {wind. }}^{\text {res. }}\left(\dot{\mathrm{W}}_{\text {wind resistance }}^{\text {rolling resistance }}\right)=0,5 \rho \cdot A \cdot C d \cdot(V+V w)^{2} V$

$$
\dot{\mathrm{W}}_{\text {total power of vehicle }}=m_{\text {fuel }} x \eta_{\text {vehicle }} x Q_{L H V}
$$

- Weight (m): Vehicles have been accepted full and an average of 16 tons was calculated.

- Acceleration of gravity ( $\mathrm{g})$ : is accepted to be an average of $9.81 \mathrm{~m} / \mathrm{s}^{2}$

- $\operatorname{Density}(\rho)$ : the air density is $1,293 \mathrm{~kg} / \mathrm{m}^{3}$

- Acceleration (a): Heavy vehicles are taken as the average of $2 \mathrm{~m} / \mathrm{s}^{2}$

- Slope angle $(\Theta)$ : the region is close 0 so angle of inclination is regarded as 0 .

- The car front projection area (A): $A=0.9$. width (4). height $(2)=7$.

- Average speed (V) : vehicles have been accepted with a full $75 \mathrm{~km} / \mathrm{h}$

- Wind speed ( $\mathrm{Vw}$ ): According to the meteorology $2 \mathrm{~m} / \mathrm{sec}$

- Wind resistance coefficient $(\mathrm{Cd})$ : is accepted as 0.3.

- Rolling resistance coefficient $\left(\mathrm{C}_{\text {roll }}\right)$ : is accepted as 0.01 (EMEP 2009)

- Efficiency: the average thermal efficiency of the internal combustion engine $30 \%$

- Minimum heating value of fuel: is taken as $40000 \mathrm{~kJ} / \mathrm{kg}$ (EMEP 2009)

The daily amount of accumulated trace elements was found by dividing the total amount of fuel by the emission factor using Formulas 1 and 2.

\section{Mapping of accumulation distribution}

The accumulation data were transferred to the GIS database and accumulation distribution was mapped using GIS software. In order to show the spatial distribution of $\mathrm{Cd}$ the accumulation maps were created using spatial interpolation methods. The results of the analysis were loaded into the Surfer program and maps were prepared by using the Kriging method. The Surfer software is a type of Geographic Information System software for spatial analysis and the Kriging Method (Golden Software 2002). Satellite images taken from Google Earth were used as base maps.

\section{Results and discussion}

\section{Cd levels in leaves}

$\mathrm{Cd}$ concentrations in the leaves of walnut and quince are shown in Table 2. The Cd concentration in leaves ranged from 0.04 to $0.11 \mathrm{mg} / \mathrm{kg}$. It should also be noted that $\mathrm{Cd}$ concentration exceeded the limit value in all samples (The limit is $0.01-0.03 \mathrm{mg} / \mathrm{kg}$ in unpolluted areas). Therefore, it can be said that washing procedure is not important for removing trace element in suburban area (Caselles et al. 2002).

It was observed that $\mathrm{Cd}$ accumulation is at the maximum level in inclined areas and in the areas which are closest to the highway.

$\mathrm{Cd}$ accumulation differences between quince and walnut leaves were ignored due to structural features of leaves and were not considered. 


\section{Results of emission inventory}

In order to determine the daily average vehicle number, the vehicles moving on the highway were counted and then categorized as a small truck, heavy vehicle, automobile or motorcycle. The obtained results given in Table 3 show that the number of total vehicles was 19,860 per day and the percent ratio of heavy vehicles $(3,786)$ to total vehicles was $19 \%$. Emissions were calculated using EMEP/EEA emission factors in formulas 1 and 2 (Table 3 ).

Total power of vehicle was calculated as $669,12 \mathrm{~kW}$ (Formula 1). By using this result, $\mathrm{m}_{\text {fuel }}$ was calculated with formula 2 and the result was $0.0558 \mathrm{~kg} \cdot$ day $^{-1}$. When this result was multiplied by the number of heavy vehicles, the result was $18,239,795 \mathrm{~kg} \cdot \mathrm{day}^{-1}$. As a result, the total fuel amount was calculated with EPA emission factor and it was determined that there were 0.18 tons of $\mathrm{Cd}$ ion emitted to the atmosphere daily and therefore, the emitted $\mathrm{Cd}$ could accumulate in the leaves of the trees. When it is considered that there are no residential areas or industrial plants around the study field, it is clear that the pollution was caused by traffic. As mentioned before, more than $40 \%$ of the accumulated $\mathrm{Cd}$ in plants near industrial and heavy traffic areas comes from the air. Because of that, the emission inventory is important in terms of emphasizing that the $\mathrm{Cd}$ accumulation was related to traffic.

\section{Demonstration of accumulation distribution by GIS}

The topographical structure of the study field was shown according to the coordinates at sample points (Figure 2). In the studies on trace elements, the topographical properties of fields from where plant samples are taken influence the amount of trace element in plants. While the amounts of trace element obtained from fields at an incline have higher values, when the study field is flat, low accumulation values are observed. In this study it is seen that the height values increased towards the north, east and west directions in the topography.

The accumulation level map prepared with the results of sample analyses is shown in Figure 3. The points of maximum $\mathrm{Cd}$ accumulation were observed at points no 1, 3, 12 and 13 (Table 2). The map shows that the maximum level of $\mathrm{Cd}$ accumulation was at the nearest point to the highway in the study areas. Obviously the amount of accumulation decreased by moving away from the highway. This fact shows that $\mathrm{Cd}$ accumulation is the result of exhaust emissions. There is no residential area nor an industrial plant in the study area and in its surroundings, hence $\mathrm{Cd}$ accumulation is related to traffic emission only. Besides, farmers use minimum amount of fertilizer according to Sakarya directorate of provincial agriculture database. The obtained results are in good agreement with previous studies reported in the literature (Maisto et al. 2004, Akyol and Öztürk 1997). GIS plays a complementary role in the presentation of accumulation and pollution distribution and also supports the decision-making process (Macit and Gümrükçüoglu 2012).

\section{Conclusion}

The levels of $\mathrm{Cd}$ found in the leaves were higher than acceptable levels. The emission inventory results indicated that the roadside $\mathrm{Cd}$ pollution was highly positively correlated with traffic density. The maximum level of $\mathrm{Cd}$ accumulation was observed in the points near the highway and decreased relative

Table 2. Cd accumulation on washed samples

\begin{tabular}{|c|c|c|}
\hline Sample & Tree & Cd mg/kg \\
\hline 1A & Quince & 0,09429 \\
\hline 2A & Walnut & 0,05676 \\
3A & Quince & 0,09391 \\
4A & Walnut & 0,04724 \\
5A & Quince & 0,05313 \\
6A & Quince & 0,07027 \\
7A & Quince & 0,06349 \\
8A & Walnut & 0,05164 \\
9A & Quince & 0,085 \\
10A & Walnut & 0,07931 \\
\hline
\end{tabular}

\begin{tabular}{|c|c|c|}
\hline Sample & Tree & Cd $\mathrm{mg} / \mathrm{kg}$ \\
\hline $11 \mathrm{~A}$ & Quince & 0,07006 \\
\hline $12 \mathrm{~A}$ & Walnut & 0,10165 \\
$13 \mathrm{~A}$ & Quince & 0,10592 \\
$14 \mathrm{~A}$ & Walnut & 0,05682 \\
$15 \mathrm{~A}$ & Quince & 0,06794 \\
$16 \mathrm{~A}$ & Quince & 0,07122 \\
$17 \mathrm{~A}$ & Quince & 0,06257 \\
$18 \mathrm{~A}$ & Walnut & 0,05093 \\
$19 \mathrm{~A}$ & Quince & 0,07655 \\
$20 \mathrm{~A}$ & Walnut & 0,07239 \\
\hline
\end{tabular}

Table 3. Average daily vehicle number

\begin{tabular}{|c|c|c|c|c|c|}
\hline & \multicolumn{4}{|c|}{ Vehicle number according to hours } & $\begin{array}{c}\text { Daily average } \\
\text { vehicle number }\end{array}$ \\
\cline { 2 - 6 } & $08.00-09.00$ & $12.00-13.00$ & $15.00-16.00$ & $19.00-20.00$ & 159 \\
\hline Small truck & 122 & 148 & 132 & 196 & 3366 \\
\hline Heavy vehicle & 158 & 142 & 135 & 496 & 12594 \\
\hline Automobile & 586 & 475 & 342 & 8 & 114 \\
\hline Motorcycle & 3 & 5 & 3 & & 8 \\
\hline
\end{tabular}



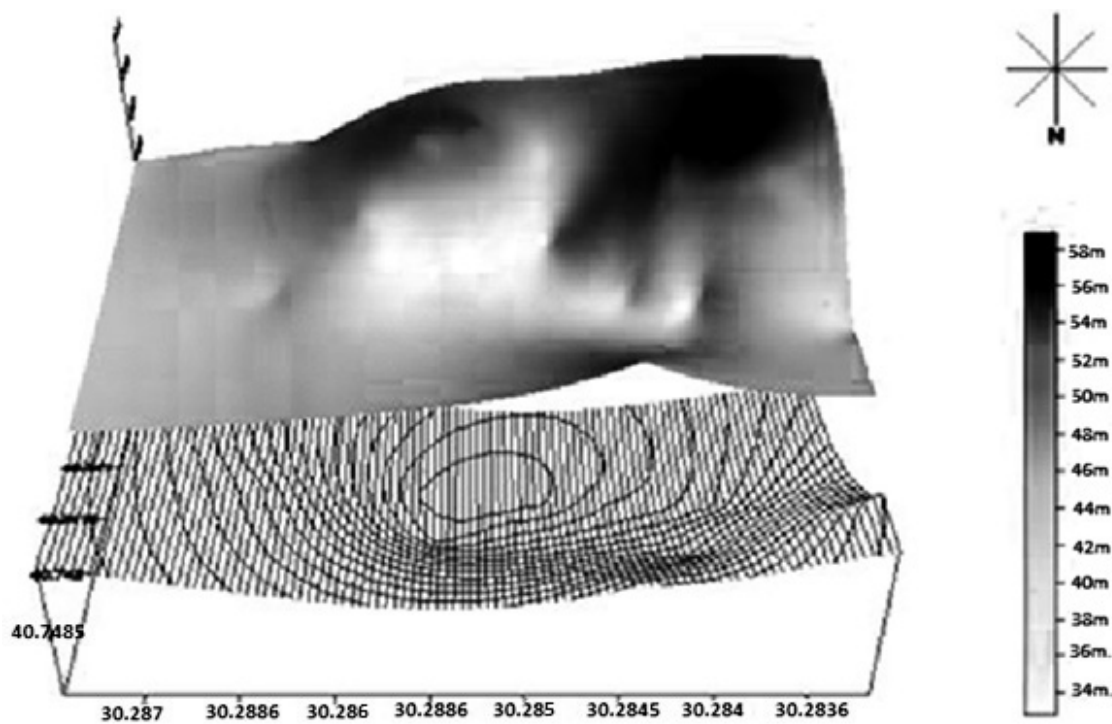

Fig. 2. Topographic structure on study area

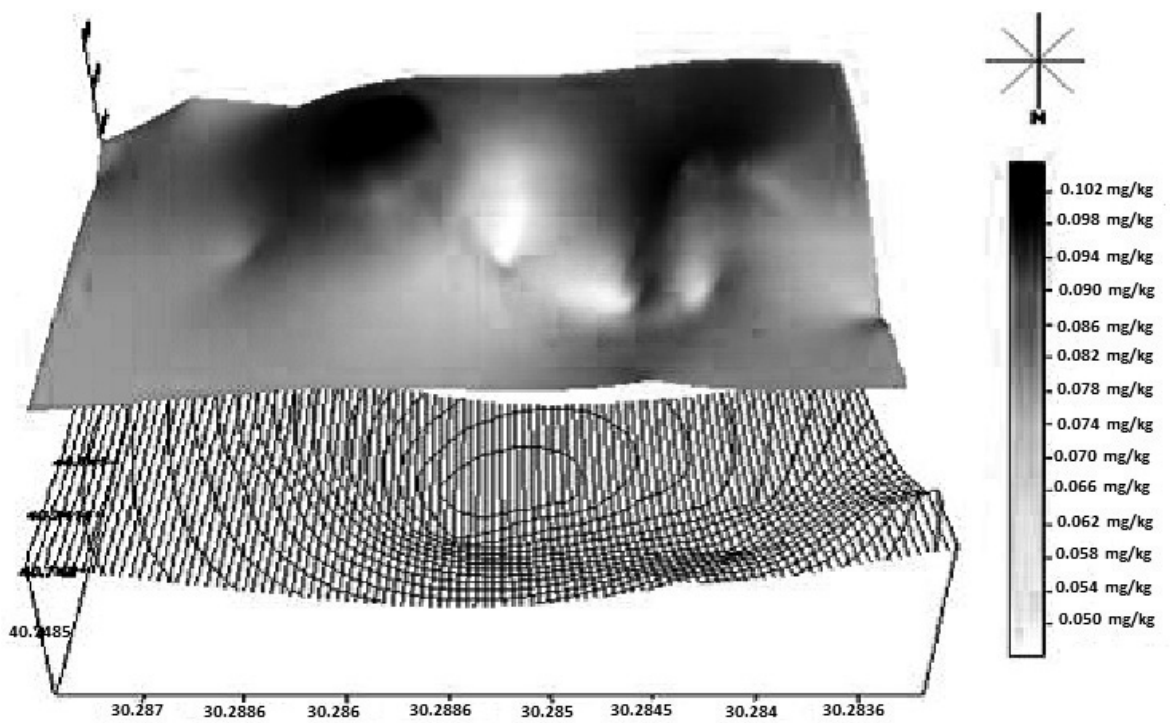

Fig. 3. Distribution of $\mathrm{Cd}$ accumulation

to the distance from the highway. $\mathrm{Cd}$ is a toxic element, so analysis of accumulation and plotting the distribution on GIS maps are important and provide invaluable information for decision makers.

\section{References}

Aksoy, A. \& Öztürk, M.A. (1997). Nerium oleander L. as a biomonitory of lead and other heavy metal pollution in Mediterranean environments, The Science of the Total Environment, 205, pp. 145-150.

Benavides, M.P., Gallego, S.M. \& Tomaro, M.L. (2005). Cadmium toxicity in plants, Brazilian Journal of Plant Physiology, 17, pp. 21-34.

Caselles, J., Colliga, C. \& Zornoza, P. (2002). Evaluation of trace element pollution from vehicle emissions inpetunia plants, Water, Air and Soil Pollution, 136, 1, pp. 1-9.

Chronopoulos, J., Haidouti, C., Chronopoulou-Serelli, A. \& Massas, I. (1997). Variations in plant and soil lead and cadmium content in urban parks in Athens, Greece, Science of The Total Environment, 196, 1, pp. 91-98.
Elbir, T., Müezzinoglu, A., Bayram, A., Seyfioğlu, R. \& Demircioğlu, H., (2001). Air pollutant emission inventory of Agean region, Dokuz Eylül University Science and Engineering Journal, 3, pp. 21-27.

EMEP/EEA. (2009). Emission Inventory Guidebook, Updated June 2010.

EPA (Environmental Protection Agency) (1987). Indoor air quality implementation plan, Washington D.C. 1987.

Golden Software, (2002). Surfer 7, User's Guide: Contouring and 3D surface mapping for scientist andengineers, Colorado USA 2002.

Haktanır, K., Arcak, S., Erpul, G. \& Tan, A. (1995). Accumulation of the vehicle-generated heavy metals on the roadside soils, Turkish Journal of Engineering \& Environmental Sciences, 19, 6, pp. 423-431.

Karademir, M. (1992). Heavy metal accumulation related to exhoust gases in grass on some crossroads of Ankara City, Master Thesis, Institute of Science, Ankara University, Turkey 1992.

Kınalıglu, K., Çavuşoglu, K., Yapar, K., Türkmen, Z., Yalçın, E., Şengül, B., Şengül, Ü. \& Duyar, Ö. (2009). Investigation of lead $(\mathrm{Pb})$ pollution related to traffic by using Usnea Longissima Acharıus, SDÜ Science Journal, 4, 2, pp. 129-135. 
Luilo, G.B. \& Othman, O.C. (2003). Heavy metal levels of pasture grasses in metropolitan area, Journal de Physique, EDP Sciences 107, pp. 801-805.

Macit, M.B. \& Gümrükçüoglu, M. (2012). Determinaton of industrial sulfur dioxide emissions and mapping by geographic information system, Polish Journal of Environmental Studies, 21, 3, pp. 549-558.

Maisto, G., Alfani, A., Baldantoni, D., De Marko, A. \& De Santo, A.V. (2004). Trace metals in the soil and inQuercus ilex L. Leaves at anthropic and remote sites of the Campania Region of Italy, Geoderma, 122, pp. 269-279.

Mendil, D. \& Tuzen, M. (2011). Assessment of trace elements in animal tissues from Turkey, Environmental Monitoring and Asessment, 182, 1-4, pp. 423-430.

Onasanya, L.O., Kola, A. \& Adeyeye, A. (1993). Lead content in roadside vegetation as indicators of atmospheric pollution, Environment International, 19, 6, pp. 615-618.

Onder, S. \& Dursun, S. (2006). Air borne heavy metal pollution of Cedrus, libani (A.Rich.) in the city centre of Konya (Turkey), Atmospheric Environment, 40, pp. 1122-1133.

Onianwa, P.C. \& Ajay, S.O. (2002). Heavy metals contents of roadside mosses in the northern and South-Easternregions of Nigeria, Chemistry and Ecology, 18, 3-4, pp. 187-194.

Sanda, A.M. (1993). Heavy metal accumulation in plant on roadside of Konya (Turkey), Master Thesis, Selcuk University, Konya, Turkey 1993.
Sawidis, T., Marnasidis, A., Zachariadis, G. \& Stratis, J. (1995). A study of air pollution with heavy metals in Thessaloniki city (Greece) using trees as biological indicators, Archives of Environmental Contamination and Toxicology, 28, 1, pp. 118-124.

Sharma, P. \& Dubey, R.S. (2005). Lead toxicity in plants, Brazilian Journal Plant Physiology, 17, pp. 35-52.

Sisman, I., Imamoglu, M. \& Aydın, A.O. (2002). Determination of heavy metals in roadside soil from Sapanca Area Highway, Turkey, Internatıonal Journal of Environment and Pollution, 17, 4, pp. 306-311.

Staszewski, T., Malawska, M., Studnik-Wójcikowska, B., Galera, H. \& Wiłkomirski, B. (2015). Soil and plants contamination with selected heavy metals in the area of a railway junction, Archives of Environmental Protection, 41, 1 pp. 35-42.

Wittig, R. (1993). General aspects of bio-monitoring heavy metals by plants. In: Markert, B. (Ed.), Plants as Biomonitors. Indicators for heavy metals in the terrestrial environment, Weinheim: $\mathrm{VCH}$ Press, pp. 3-27.

Xiong, Z.T. (1997). Bioaccumulation and physiological effects of excess lead in a roadside pioneer species Sonchus Oleraceus L., Environmental Pollution, 97, 3, pp. 275-279.

Yassoglou, N., Kosmas, C., Asimakopoulos, J. \& Kallianou, C. (1987). Heavy metal contamination of roadside in the greater Athens area, Environmental Pollution, 47, 4, pp. 293-304. 